\title{
Opioid receptors mediate direct predictive fear learning: Evidence from one-trial blocking
}

\author{
Sindy Cole and Gavan P. McNally ${ }^{1}$ \\ School of Psychology, The University of New South Wales, Sydney 2052, Australia
}

\begin{abstract}
Pavlovian fear learning depends on predictive error, so that fear learning occurs when the actual outcome of a conditioning trial exceeds the expected outcome. Previous research has shown that opioid receptors, including $\mu$-opioid receptors in the ventrolateral quadrant of the midbrain periaqueductal gray (vIPAG), mediate such predictive fear learning. Four experiments reported here used a within-subject one-trial blocking design to study whether opioid receptors mediate a direct or indirect action of predictive error on Pavlovian association formation. In Stage I, rats were trained to fear conditioned stimulus (CS) A by pairing it with shock. In Stage II, CSA and CSB were co-presented once and co-terminated with shock. Two novel stimuli, CSC and CSD, were also co-presented once and co-terminated with shock in Stage II. The results showed one-trial blocking of fear learning (Experiment 1) as well as one-trial unblocking of fear learning when Stage II training employed a higher intensity footshock than was used in Stage I (Experiment 2). Systemic administrations of the opioid receptor antagonist naloxone (Experiment 3) or intra-vIPAG administrations of the selective $\mu$-opioid receptor antagonist CTAP (Experiment 4) prior to Stage II training prevented one-trial blocking. These results show that opioid receptors mediate the direct actions of predictive error on Pavlovian association formation.
\end{abstract}

Learning about the predictive relations existing between events in the world is central to adaptive behavior. It allows us to use the past to predict the future and to adjust our behavior accordingly. Prediction has been formalized in experimental psychology through error-correcting learning rules (Dickinson 1980; Rescorla 1988). In Pavlovian conditioning these rules state that fear accrues to a conditioned stimulus (CS) which signals an aversive unconditioned stimulus (US) when the actual outcome of the conditioning trial exceeds the predicted outcome, i.e., when there is a positive prediction error. Likewise, fear to a CS will typically be lost when the predicted outcome exceeds the actual outcome, i.e., when there is a negative prediction error. The paradigmatic demonstration of a role for predictive error in learning is "blocking". Kamin $(1968,1969)$ subjected rats to CSA-shock pairings. In Stage II, rats received a compound stimulus of CSA and CSB paired with shock. A control group received Stage II training but no Stage I training. The control group showed robust fear of CSB. However, for the experimental group learning to CSB failed. Conditioning failed to $\mathrm{CSB}$, despite $\mathrm{AB}$-shock pairings, because predictive error during Stage II was low: Subjects could predict the occurrence of shock from CSA and so learning about CSB was "blocked."

The neural mechanisms for the encoding, storage, and retrieval of fear memories are remarkably well understood. Activation of NMDA receptors in the amygdala and recruitment of the signal transduction cascades subsequent to NMDA receptor activation (e.g., $\mathrm{Ca}^{2+}$ and cyclic AMP-dependent signaling) are essential for fear memory formation (for example, see Schafe et al. 2001; Maren and Quirk 2004). In contrast, the neural mechanisms of predictive fear learning remain poorly understood. Using a within-subject blocking design, McNally and Cole (2006) demonstrated that $\mu$-opioid receptors in the ventrolateral quadrant of the midbrain periaqueductal gray (vlPAG) mediate predictive error during fear learning. Rats were conditioned to fear CSA via pairings with footshock. In Stage II an AB compound and a CD compound were both paired with footshock. On test the

${ }^{1}$ Corresponding author.

E-mail g.mcnally@unsw.edu.au; fax 61-2-93853044.

Article is online at http://www.learnmem.org/cgi/doi/10.1101/lm.489507. rats displayed more fear to $\mathrm{D}$ than $\mathrm{B}$, indicating that the previously trained CSA had blocked conditioning to B. This blocking was prevented (i.e., fear accrued normally to B) if Stage II training was preceded by either systemic injections of the opioid receptor antagonist naloxone or intra-vlPAG infusions of the $\mu$-opioid receptor selective antagonist CTAP.

The actions of predictive error on Pavlovian association formation can be direct or indirect (McNally and Westbrook 2006). A direct action on association formation is achieved by altering the effectiveness of the shock US. A US which is surprising or unexpected is more effective at promoting learning than an unsurprising US (for example, see Rescorla and Wagner 1972). Predictive error can also have an indirect action by regulating the attention allocated to the CS (for example, see Mackintosh 1975a). A CS which is a better predictor of the outcome will command more attention and consequently be better learned about than a CS which is a poorer predictor and which is consequently ignored. McNally and Cole (2006) demonstrated that vlPAG $\mu$-opioid receptors contribute to predictive fear learning. However, the design of those experiments did not permit examination of whether this $\mu$-opioid receptor contribution to predictive fear learning was direct and achieved via alterations in US processing or indirect and achieved via alterations in CS processing.

Numerous behavioral designs permit selection between these possibilities (McNally and Westbrook 2006). However, perhaps the simplest approach is a variation of the standard blocking design. According to theories of direct predictive fear learning, blocking occurs due to the unsurprising US in Stage II being a less effective reinforcer. In contrast, according to theories of indirect predictive fear learning, blocking occurs because the added CS in Stage II is a poorer predictor of the US than the pretrained CS and so on subsequent trials the added CS is ignored. This withdrawal of attention from the added CS takes place across multiple Stage II trials, and so attentional theories predict that blocking does not occur when a single Stage II conditioning trial is used. In contrast, theories of direct predictive learning predict such one-trial blocking. In these experiments we used a within-subject one-trial blocking design to study how opioid receptors regulate predictive fear learning. 


\section{Results}

Experiment 1: One-trial blocking of fear learning

Blocking of fear learning with multiple Stage II trials is a robust phenomenon (for example, see Kamin 1968; McNally et al. 2004a). However, evidence for one-trial blocking in a number of preparations has been mixed (for example, see Mackintosh 1975b; Gillan and Domjan 1977; Mackintosh et al. 1980; Dickinson et al. 1983). In a typical blocking experiment, CSA is paired with shock in Stage I and the compound of CSA and CSB paired with shock in Stage II. Generally, one-trial blocking is less likely to occur under circumstances that favor formation of higherorder associations between CSA and CSB during Stage II, thereby supporting the second-order conditioning of fear to B (for example, see Dickinson et al. 1983). In this experiment we used a within-subjects preparation to compare blocking with one or two trials during Stage II to determine the utility of a within-subjects design in detecting one-trial blocking of fear conditioning. The design is shown in Table 1. Animals were initially trained to fear CSA via pairings with footshock. In Stage II an AB compound and a CD compound were both paired with footshock. Animals in group two-trial $(n=8)$ received two reinforced presentations each of $\mathrm{AB}$ and $\mathrm{CD}$, while those in group one-trial $(n=8)$ received a single reinforced presentation of each compound. Fear responses to $\mathrm{B}$ and $\mathrm{D}$ were then tested. It is worth emphasizing that the purpose of this experiment is not to compare overall levels of fear between group two-trial and group one-trial. The purpose of the experiment is to study the within-subjects difference between $B$ and $\mathrm{D}$ for these groups. Theories of direct and indirect predictive learning make qualitatively, not quantitatively, different predictions. Theories of direct predictive learning predict $\mathrm{B}<\mathrm{D}$ for both groups one-trial and two-trial. In contrast, theories of indirect predictive learning predict $\mathrm{B}=\mathrm{D}$ for group one-trial and $\mathrm{B}<\mathrm{D}$ for group two-trial.

The left panel of Figure 1 shows mean ( \pm standard error of the mean [SEM]) levels of freezing during the first presentation of CSA on each day of Stage I training. From inspection of this figure it is apparent that fear accrued to CSA across days of Stage I training for both groups. This was confirmed by the increase in levels of freezing across the two days of training $\left(F_{(1,14)}=816.2\right.$; $P<0.05$ ). There was no significant effect for group (one-trial vs. two-trial) during Stage I $\left(F_{(1,14)}<1.0 ; P>0.05\right)$, indicating that groups showed equivalent levels of freezing. There was also no significant interaction of group and day $\left(F_{(1,14)}<1.0 ; P>0.05\right)$.

The middle panel of Figure 1 shows mean ( \pm SEM) levels of freezing during Stage II training. It is apparent that on the initial compound presentations in Stage II training fear was higher to

Table 1. Experimental design

\begin{tabular}{|c|c|c|c|}
\hline Experiment & Stage I & Stage II & Test \\
\hline Experiment 1 & $\mathrm{~A}+$ & $\begin{array}{c}A B+, C D+ \\
A B+, A B+C D+, C D+\end{array}$ & B vs. D \\
\hline Experiment 2 & $A+$ & $\begin{array}{c}\mathrm{AB}+\mathrm{CD}+ \\
\mathrm{AB}++, \mathrm{CD}++\end{array}$ & B vs. D \\
\hline Experiment 3 & A+ & $\begin{array}{c}\text { Naloxone: } A B+, C D+ \\
\text { Saline: } A B+, C D+\end{array}$ & B vs. D \\
\hline Experiment 4 & $\mathrm{~A}+$ & $\begin{array}{l}\text { CTAP: } A B+, C D+ \\
\text { Saline: } A B+, C D+\end{array}$ & B vs. D \\
\hline
\end{tabular}

$A$ and $C$ were $30-s e c$ visual conditioned stimuli (CSs; light or flashing light). B and D were $30-$ sec auditory CSs (clicker or tone). CSs were fully counterbalanced. +, a $1-\mathrm{sec} 0.5-\mathrm{mA}$ footshock unconditioned stimulus (US). ++, a 1-sec 0.8-mA footshock US. The opioid receptor antagonist naloxone was injected subcutaneously. The $\mu$-opioid receptor selective antagonist CTAP was microinjected into ventrolateral periaqueductal gray $(0.5 \mu \mathrm{g} / 0.5 \mu \mathrm{L})$.

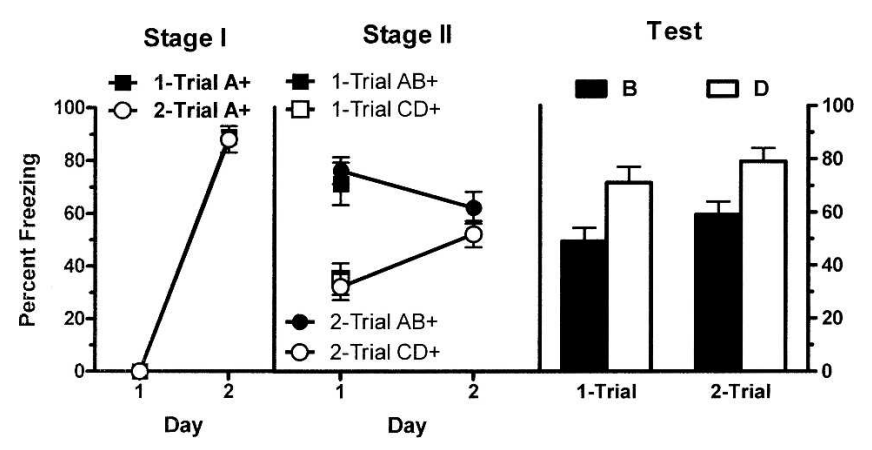

Figure 1. Mean ( \pm SEM) levels of freezing in Experiment 1. A and $C$ were 30 -sec visual conditioned stimuli (CSs); B and D were 30 -sec auditory CSs. Freezing developed to A during Stage I (left panel) and to the $C D$ compound during Stage II (middle panel). Performance on testing shows that conditioned fear to $B$ was less than to $D(P<0.05)$, indicating the presence of blocking. This effect did not differ across groups $(P>0.05)$. + indicates the presence of footshock with the CS.

$\mathrm{AB}$ than $\mathrm{CD}$ for both groups (because A had previously been paired with shock). This was confirmed by a significant main effect for stimulus type (AB vs. $\mathrm{CD})\left(F_{(1,14)}=84.04 ; P<0.05\right)$. There was no significant effect of group (one-trial vs. two-trial) $\left(F_{(1,14)}<1.0 ; P>0.05\right)$ and no significant interaction effect of group and stimulus type $\left(F_{(1,14)}<1.0 ; P>0.05\right)$. It is also clear that fear to CD increased across training for group two-trial. On the second trial there was no significant effect for stimulus type indicating equivalent levels of fear to the compounds $\mathrm{AB}$ and $\mathrm{CD}$ $\left(F_{(1,14)}=1.59 ; P>0.05\right)$. There was no significant difference between groups in pre-CS freezing $(t=0.56 ; P>0.05)$.

The right panel of Figure 1 shows mean $( \pm$ SEM) levels of freezing during the test presentations of CSB and CSD. Inspection of this figure suggests that there was more fear to stimulus D than stimulus B among both groups. This was confirmed by the significant main effect of stimulus type (B vs. D) $\left(F_{(1,14)}=26.16\right.$; $P<0.05$ ). There was no significant effect for group (one-trial vs. two-trial) $\left(F_{(1,14)}=1.93 ; P>0.05\right)$, indicating that groups showed equivalent levels of freezing overall. There was also no significant interaction effect of group and stimulus $\left(F_{(1,14)}<1.0 ; P>0.05\right)$. Levels of pre-CS freezing were low (mean $=32 \%$; SEM $=4 \%$ ) and an independent samples $t$-test confirmed there was no significant difference between groups $(t=0.05 ; P>0.05)$.

These results demonstrate that under present conditions a within-subject design can detect one-trial blocking of fear learning $(\mathrm{B}<\mathrm{D})$ and that the strength of this one-trial blocking is equivalent to using multiple Stage II trials. This is consistent with direct predictive fear learning accounts that attribute blocking to the effectiveness of the US as a reinforcer and consequently allow for single-trial blocking. In contrast, according to attentional theories blocking occurs on the second trial due to a withdrawal of attention. If predictive error were acting indirectly on learning via modulating attention, blocking would be absent after a single Stage II trial, but present after two Stage II trials. However, this did not occur.

\section{Experiment 2: One-trial unblocking of fear learning}

Blocking can be abolished by an increase in reinforcer magnitude from Stage I to Stage II (so-called unblocking) (Kamin 1968, 1969). The aim of this experiment was to study one-trial unblocking. The design is shown in Table 1 . All animals were initially trained to fear CSA via pairings with a $0.5-\mathrm{mA}$ footshock. Then all animals received a single reinforced presentation of each $\mathrm{AB}$ and CD. For group block $(n=7)$ the reinforcer magnitude remained at $0.5 \mathrm{~mA}$; however, for group unblock $(n=8)$ the compounds were 


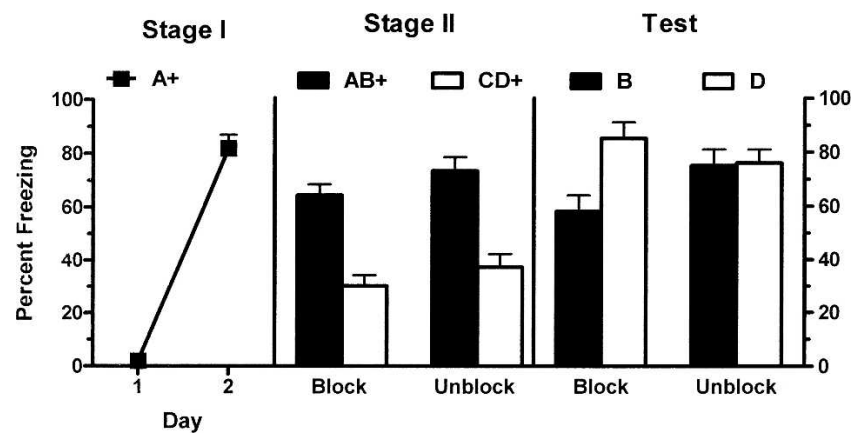

Figure 2. Mean ( \pm SEM) levels of freezing in Experiment 2. Freezing developed to A during Stage I pairings with a $0.5-\mathrm{mA}$ footshock (left panel). Performance on test shows that animals given a $0.5-\mathrm{mA}$ footshock during Stage II (group block) demonstrate blocking $(B<D)$ while animals that received a 0.8-mA footshock in Stage II (group unblock) fail to show blocking $(B=D)(P<0.05) .+$ indicates the presence of footshock with the CS.

reinforced with a $0.8 \mathrm{~mA}$ footshock. The question of interest was whether an increase in US magnitude from $0.5 \mathrm{~mA}$ in Stage I to $0.8 \mathrm{~mA}$ in Stage II would produce unblocking.

The left panel of Figure 2 shows mean $( \pm$ SEM) levels of freezing during the first presentation of CSA on each day of Stage I training. Fear accrued to CSA across days of Stage I training for both groups. This was confirmed by the increase in levels of freezing across the two days of training $\left(F_{(1,13)}=325.5 ; P<0.05\right)$. There was no significant effect for group (block vs. unblock) during Stage I $\left(F_{(1,13)}<1.0 ; P>0.05\right)$, indicating that groups showed equivalent levels of freezing. There was also no significant interaction effect of group and day $\left(F_{(1,13)}=1.05 ; P>0.05\right)$. The middle panel of Figure 2 shows mean $( \pm$ SEM) levels of freezing during Stage II training. Fear was higher to AB than CD for both groups. This was confirmed by a significant main effect for stimulus type $(\mathrm{AB}$ vs. $\mathrm{CD})\left(F_{(1,13)}=61.87 ; P<0.05\right)$. There was no significant effect found for group (block vs. unblock) $\left(F_{(1,13)}=2.57\right.$; $P>0.05)$, indicating that groups displayed equivalent levels of freezing and no significant interaction of group and stimulus type $\left(F_{(1,13)}<1.0 ; P>0.05\right)$. There was no significant difference between groups in pre-CS freezing $(t=0.03 ; P>0.05)$.

The right panel of Figure 2 shows mean $( \pm$ SEM) levels of freezing during the test presentations of CSB and CSD. There was more freezing to stimulus $\mathrm{D}$ than stimulus $\mathrm{B}$ in group block but equivalent levels of freezing to $\mathrm{B}$ and $\mathrm{D}$ in group unblock. There was no significant main effect for group (block vs. unblock) $\left(F_{(1,13)}<1 ; P>0.05\right)$, indicating that overall groups showed equivalent levels of freezing. There was a significant main effect for stimulus type (B vs. D) $\left(F_{(1,13)}=6.87 ; P<0.05\right)$ so that overall there was more freezing to D than B. Importantly, there was a significant interaction between group and stimulus type $\left(F_{(1,13)}=5.51 ; P<0.05\right)$. From inspection of Figure 2 it is clear that the difference in freezing between $\mathrm{B}$ and $\mathrm{D}$ was significantly greater among group block compared with group unblock animals. Levels of pre-CS freezing were low (mean $=41 \%$; SEM $=6 \%$ ) and an independent samples $t$-test confirmed there was no significant difference between groups $(t=0.51 ; P>0.05)$. These results confirm the one-trial blocking of fear learning and show that blocking can be prevented if US intensity is increased from Stage I to Stage II (i.e., unblocking occurs).

\section{Experiment 3: Effects of naloxone on one-trial blocking of fear learning}

Previous studies have shown that systemic administrations of naloxone prevent the blocking of conditioned fear (Fanselow and Bolles 1979; Matzel et al. 1988; McNally et al. 2004a; McNally and Cole 2006). However, these studies have focused on multi-trial blocking. The aim of Experiment 3 was to determine whether opioid receptors contribute to direct predictive fear learning by using one-trial blocking. The design is shown in Table 1. Prior to Stage II training animals received systemic injections of either naloxone $(n=8)$ or saline $(n=7)$.

The left panel of Figure 3 shows mean $( \pm$ SEM) levels of freezing during the first presentation of CSA on each day of Stage I training. There was a significant increase in levels of freezing across the two days of training $\left(F_{(1,13)}=264.1 ; P<0.05\right)$. There was no significant effect for group (naloxone vs. saline) during Stage I $\left(F_{(1,13)}=1.8 ; P>0.05\right)$, indicating that groups showed equivalent levels of freezing. There was also no significant interaction effect of group and day $\left(F_{(1,13)}=1.8 ; P>0.05\right)$. The middle panel of Figure 3 shows mean ( \pm SEM) levels of freezing during Stage II training. There was a significant main effect for Stage II drug (naloxone vs. saline) $\left(F_{(1,13)}=6.99 ; P<0.05\right)$ so that overall naloxone-treated rats showed more freezing than saline-treated rats. A significant main effect for stimulus type (AB vs. $C D$ ) indicated more freezing to the $\mathrm{AB}$ presentation than to $\mathrm{CD}$ $\left(F_{(1,13)}=52.75 ; P<0.05\right)$. There was no significant interaction between the effect of naloxone versus saline and stimulus type in Stage II $\left(F_{(1,13)}=0.00 ; P>0.05\right)$, showing that the difference in response to $\mathrm{AB}$ and $\mathrm{CD}$ during Stage II training was identical in saline- and naloxone-treated animals. There was no significant difference between groups in pre-CS freezing $(t=0.72 ; P>0.05)$.

The right panel of Figure 3 shows mean $( \pm$ SEM) levels of freezing during the test presentations of CSB and CSD. There was a significant main effect for Stage II drug (naloxone vs. saline) $\left(F_{(1,13)}=7.48 ; P<0.05\right)$ so that overall naloxone-treated rats showed more freezing than saline-treated rats. There was a significant main effect for stimulus type (B vs. D) $\left(F_{(1,13)}=6.45\right.$; $P<0.05)$ so that overall there was more freezing to $\mathrm{D}$ than $\mathrm{B}$. Importantly, there was a significant interaction between Stage II drug (naloxone vs. saline) and stimulus type (B vs. D) $\left(F_{(1,13)}=4.89 ; P<0.05\right)$. From inspection of Figure 3 it is clear that the difference in freezing between $\mathrm{B}$ and $\mathrm{D}$ was significantly greater among saline-treated animals compared with naloxonetreated animals. Analyses of simple effects were used to directly confirm this interpretation. Naloxone-treated animals displayed significantly more fear to $B$ than saline-treated animals $\left(F_{(1,13)}=9.09 ; P<0.05\right)$; however, these groups did not differ significantly in levels of fear to $\mathrm{D}\left(F_{(1,13)}=0.61 ; P>0.05\right)$. Levels of pre-CS freezing were low (mean $=17 \%$; SEM $=5 \%$ ) and there was no significant difference between groups $(t=0.31 ; P>0.05)$.

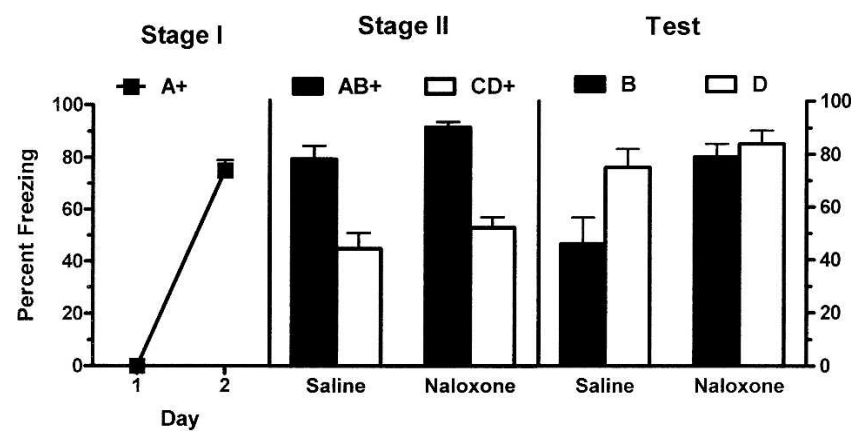

Figure 3. Mean $( \pm$ SEM) levels of freezing in Experiment 3. Freezing developed to A during Stage I (left panel). There was no effect of naloxone during Stage II training (middle panel). Performance during testing shows the presence of blocking $(B<D)$ in rats injected with saline prior to Stage II but not in the rats injected with naloxone in Stage II $(B=D)$ $(P<0.05) .+$ indicates the presence of footshock with the CS. 
Thus, systemically administered naloxone prevents one-trial blocking of fear learning.

\section{Experiment 4: Effects of intra-vIPAG CTAP on one-trial blocking of fear learning}

McNally and Cole (2006) showed that infusions of the selective $\mu$-opioid receptor antagonist CTAP prevented blocking in a multi-trial procedure. This prevention of blocking by CTAP was dose-dependent and was neuroanatomically specific to the vlPAG. In Experiment 4 we studied the role of vlPAG $\mu$-opioid receptor in one-trial blocking of fear learning. The design is shown in Table 1 . Both groups received Stage I training. Before Stage II training animals received an infusion into vlPAG of either the $\mu$-opioid receptor selective antagonist $0.5 \mu \mathrm{g}$ CTAP or saline. The question of interest was whether infusions of CTAP into the vlPAG would prevent one-trial blocking.

\section{Histology}

Figure 4 shows the location of the microinjection tips for the rats in this experiment. Two rats receiving CTAP were excluded from the primary analysis as a result of misplaced cannulae. The locations of these misplaced cannulae are also indicated in Figure 4.

\section{Behavior}

The left panel of Figure 5 shows mean $( \pm$ SEM) levels of freezing during the first presentation of CSA on each day of Stage I training. There was a significant increase in levels of freezing across the two days of training $\left(F_{(1,12)}=1882.88 ; P<0.05\right)$. There was no significant effect for group (CTAP vs. saline) during Stage I $\left(F_{(1,12)}<1 ; P>0.05\right)$, indicating that groups showed equivalent levels of freezing. There was also no significant interaction effect of group and day $\left(F_{(1,12)}<1 ; P>0.05\right)$. The middle panel of Figure 5 shows mean $( \pm$ SEM) levels of freezing during Stage II training. There was no significant main effect for Stage II drug (CTAP vs. saline) $\left(F_{(1,12)}<1 ; P>0.05\right)$ so that overall groups showed equivalent levels of freezing. A significant main effect for stimulus type ( $\mathrm{AB}$ vs. $\mathrm{CD}$ ) was found indicating that overall there was more freezing to the $\mathrm{AB}$ presentation than to $\mathrm{CD}\left(F_{(1,12)}=44.02\right.$; $P<0.05)$. There was no significant interaction between the effect of CTAP versus saline and stimulus type in Stage II $\left(F_{(1,12)}<1\right.$; $P>0.05)$, showing that the difference in response to $\mathrm{AB}$ and $\mathrm{CD}$ during Stage II training was identical in saline- and CTAP-treated animals. There was no significant difference between groups in pre-CS freezing $(t=1.99 ; P>0.05)$.

The right panel of Figure 5 shows mean $( \pm$ SEM) levels of

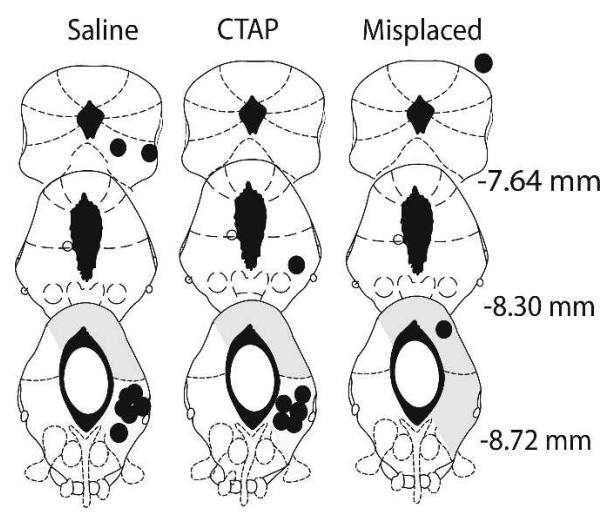

Figure 4. Cannula placement in the periaqueductal gray. Illustration of injection cannula placements for Experiment 4 is shown. Placements represented are from all rats included in the final analysis. Atlas templates were adapted from Paxinos and Watson (1998) (distances in millimeters from bregma).

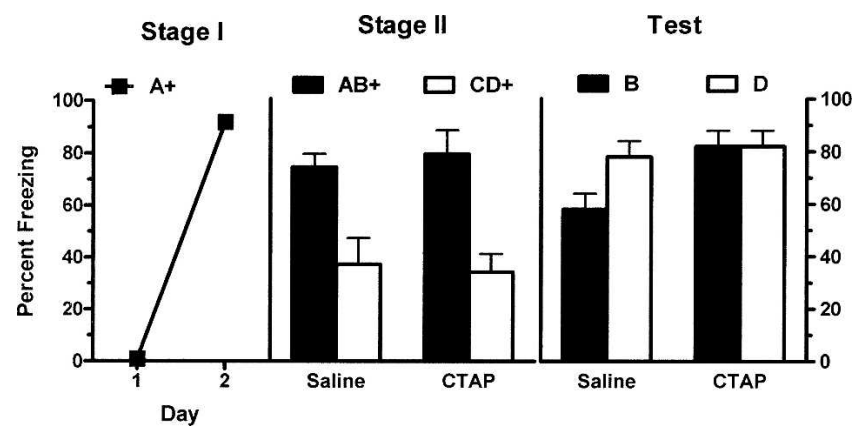

Figure 5. Mean $( \pm S E M)$ levels of freezing in Experiment 4. Freezing developed to A during Stage I (left panel). There was no effect of vIPAG microinjections of the $\mu$-opioid receptor antagonist CTAP $(0.5 \mu \mathrm{g} / 0.5 \mu \mathrm{L})$ during Stage II training (middle panel). Performance during testing shows the presence of blocking $(B<D)$ in rats microinjected with saline prior to Stage II but not in the rats microinjected with CTAP prior to Stage II $(B=D)(P<0.05) .+$ indicates the presence of footshock with the CS.

freezing during the test presentations of CSB and CSD. There was no main effect of Stage II drug treatment (CTAP vs. saline) $\left(F_{(1,12)}=3.02 ; P>0.05\right)$. A significant main effect of CS type (B vs. D) was found $\left(F_{(1,12)}=5.5 ; P<0.05\right)$ so that there was significantly more freezing to D than B. Importantly, there was a significant interaction between these variables (Stage II drug treatment and CS type) $\left(F_{(1,12)}=5.5 ; P<0.05\right)$. From inspection, this indicates that the difference between $\mathrm{B}$ and $\mathrm{D}$ was significantly greater among saline-treated compared with CTAP-treated animals. Further statistical analysis of simple effects confirmed this interpretation. The CTAP group showed significantly more fear to $\mathrm{B}$ than did the saline group $\left(F_{(1,12)}=7.1 ; P<0.05\right)$, however these groups did not differ significantly in levels of fear to $D$ $\left(F_{(1,12)}<1 ; P>0.05\right)$. Levels of pre-CS freezing were low (mean $=21 \%$; SEM $=6 \%$ ), and an independent samples $t$-test confirmed there was no significant difference between groups $(t=1.18 ; P>0.05)$. Thus, vlPAG microinjections of the $\mu$-opioid receptor antagonist CTAP prevented one-trial blocking.

At the level of the midbrain studied in this experiment, $\mu$-opioid receptors are expressed most densely in vlPAG (for example, see Gutstein et al. 1998). This fact combined with the use of relatively small microinjection volumes $(0.5 \mu \mathrm{L})$ argues against any effect of CTAP at a site distant from microinjection. To further study neuroanatomical specificity, we examined the performances of animals infused with CTAP but excluded from the original analysis due to misplaced cannulae. One was located in the lateral PAG, the other was dorsal and rostral to PAG (Fig. 4). We constructed $95 \%$ confidence intervals for performance to B and $\mathrm{D}$ for saline and CTAP groups to estimate the relevant population means, and then examined the performance of the two misplaced CTAP animals relative to these parameter estimates (Table 2). For both misplaced animals, freezing to B fell below the lower bound of the $95 \%$ confidence intervals for mean performance for vlPAG CTAP. In contrast, their performance to the

Table 2. Ninety-five percent confidence intervals for freezing to CSB and D for groups saline and CTAP in and performances of animals with misplaced cannulae in Experiment 4

\begin{tabular}{lccccc}
\hline & \multicolumn{2}{c}{ B } & & \multicolumn{2}{c}{ D } \\
\cline { 2 - 3 } & Lower & Upper & & Lower & Upper \\
\hline Saline & $44 \%$ & $72 \%$ & & $65 \%$ & $92 \%$ \\
CTAP & $68 \%$ & $97 \%$ & & $68 \%$ & $97 \%$ \\
\hline Misplaced & \multicolumn{2}{c}{$43 \%, 63 \%$} & & \multicolumn{2}{c}{$73 \%, 87 \%$} \\
\hline
\end{tabular}


blocked CS, B, was on or within the bounds of the $95 \%$ confidence interval for mean performance for vlPAG saline. This confirms our previous evidence (McNally et al. 2004b; McNally and Cole 2006) that only vlPAG microinjections of opioid receptor antagonists influence predictive fear learning.

\section{Discussion}

Predictive error regulates Pavlovian association formation. Such error can have a direct effect on fear learning by influencing the reinforcing efficacy of the shock US or it can have an indirect effect on fear learning by regulating the attention allocated to a CS. The one-trial blocking design used here permits discrimination between these two actions because one-trial blocking can only be explained by a direct action of predictive error on learning. This design generates different prediction errors for $\mathrm{B}$ and $\mathrm{D}$ during Stage II. The prediction error for B is low. Prior to Stage II it has not been paired with shock, and during Stage II it is being conditioned in compound with A which was previously paired with shock. In contrast, the prediction error for $\mathrm{D}$ is large because neither it nor $\mathrm{C}$ has been paired previously with shock. A direct action of this prediction error should cause more learning to D than B during Stage II, and so on test rats should show more fear of D than B. An indirect action of this prediction error would have no influence on the first Stage II trial but instead would feed forward to any subsequent trials, causing subjects to withdraw their attention from B. Because only a single Stage II trial was used in these experiments, there was no opportunity for subjects to withdraw their attention from $\mathrm{B}$, so learning about $\mathrm{D}$ and $\mathrm{B}$ should have been equal. The results consistently showed evidence for one-trial blocking of fear learning: Fear to B was less than fear to D.

Blocking could be prevented if Stage II training employed a higher intensity shock than Stage I (Experiment 2). Increasing the Stage II US increases predictive error because it increases the actual outcome of the trial relative to the expected outcome from Stage I training. This demonstration of unblocking is important for two reasons. First, it shows that one-trial blocking of fear learning is sensitive to the same variables as multi-trial blocking. Increases in US intensity or duration consistently produce unblocking of fear in preparations using multiple Stage II trials (for example, see Kamin 1968, 1969; Wagner et al. 1980; McNally et al. 2004a). This excludes the possibility that one-trial blocking is due to competition for limited processing resources (for example, see James and Wagner 1980). Second, this one-trial unblocking cannot be explained by indirect predictive learning because the indirect effects of a change in US intensity are only manifest across multiple trials. Taken together, these results show that under the conditions used here, the within-subject blocking design was sensitive to the direct effects of predictive error on fear learning.

One-trial blocking was prevented by systemic naloxone (Experiment 3) or intra-vlPAG CTAP (Experiment 4). Our results therefore show for the first time that opioid receptors mediate direct predictive fear learning. The logic of the experimental design is such that for saline control rats the predictive error for $\mathrm{AB}$ during Stage II was small (A already predicted the shock), so formation of a B-US association is blocked. In contrast, for rats systemically injected with naloxone or microinjected with CTAP into the vlPAG, the B-shock association was not blocked. This prevention of blocking occurs despite the naloxone- and CTAPtreated rats displaying the A-shock association by their high levels of fear on the AB trial of Stage II. This prevention of blocking was specific. It was not due to a general permissive effect of opioid receptor antagonism on fear learning or memory consolidation because neither systemic naloxone nor intra-vlPAG CTAP had any effect on fear conditioning to D. Blocking was also not due to differences in sensitivity to the shock US, differences in perception of the CSs, alterations in memory processing, or nonspecific effects on fear or freezing because the within-subjects design equated all subjects on exposure to all stimuli. Rather, systemic or vlPAG $\mu$-opioid receptor antagonism acted selectively to prevent blocking to $\mathrm{B}$. This reveals that opioid receptor antagonism increased predictive error during Stage II and so shows that endogenous opioids act to directly decrease predictive error during fear learning.

These results support recent accounts of how predictive fear learning occurs in the mammalian central nervous system. Fanselow (1998) has suggested that opioid receptors contribute to predictive fear learning because they mediate a conditioned analgesic response which impairs detection of the shock US. According to this line of reasoning, presentation of a fear CS recruits descending antinociceptive pathways that begin in the central nucleus of the amygdala and project via the vlPAG to the rostral ventromedial medulla and, in turn, via the dorsolateral funiculus to the spinal cord dorsal horn (Fanselow 1998; McNally 1999). Alternatively, McNally and colleagues (McNally et al. 2004a,b; McNally and Cole 2006) have suggested that this opioid receptor contribution can be distinguished from pain modulation and is due to a role of vlPAG in ascending US pathways, possibly via extensive vlPAG projections to midline and intralaminar thalamic nuclei (Krout and Loewy 2000). Despite these differences, both models predict that vIPAG opioids have a direct action on predictive fear learning by regulating the efficacy of the shock US as a teaching or reinforcement signal. These results support these accounts. In contrast, a recent computational model of predictive fear learning suggests otherwise (Padlubnaya et al. 2006). Padlubnaya et al. (2006) suggest that a CS-triggered opioid response is too slow to cause blocking of fear learning. In this case, the simulations specifically assumed that an opioid response was dependent on outputs from central amygdala. The simulations, instead, suggested that a fast acting inhibitory neurotransmitter, such as GABA, was involved in blocking. The role for other neurotransmitters and neuromodulators in blocking of fear learning remains an open empirical question, as does the dependence or otherwise of vlPAG $\mu$-opioid receptor contributions on amygdala output. However the present data show that the actions of vlPAG $\mu$-opioid receptors are central to the associative blocking of fear learning.

Finally, it is worth noting this role of vlPAG $\mu$-opioid receptors in predictive fear learning complements the role of $\mu$-opioid receptors in the ventral striatum, specifically the nucleus accumbens. Iordanova et al. (2006) used blocking and unblocking of fear learning to study the role of $\mu$-opioid receptors in the nucleus accumbens in indirect predictive fear learning. Iordanova et al. (2006) showed that accumbal $\mu$-opioid receptors were important for increments in CS processing as a consequence of predictive error. Taken together, these findings show a dual role for opioids in regulating predictive fear learning depending on their neuroanatomical location. In nucleus accumbens, $\mu$-opioid receptors up-regulate attention to CSs that are predictive of shock and thereby contribute to indirect predictive fear learning. In vlPAG, $\mu$-opioid receptors regulate the efficacy of the shock US as a teaching or reinforcement signal and thereby contribute to direct predictive fear learning. Further research is needed to clarify the interactions between these different opioid contributions as well to determine how these contributions influence amygdala-dependent fear memory formation.

\section{Materials and Methods}

\section{Subjects}

The subjects were experimentally naive, adult, male Wistar rats (220-280 g) obtained from a commercial supplier (Gore Hill Re- 
search Laboratories). After arrival, rats were housed in groups of eight in plastic cages and maintained on a 12-h light-dark cycle (lights on at 7 a.m.) with free access to food and water. The rats were handled (1-2 min per rat per day) for $3 \mathrm{~d}$ to habituate them to the experimenter. The procedures used were approved by the Animal Ethics Committee at the University of New South Wales and were conducted in accordance with the National Institutes of Health's (1986) Guide for the Care and Use of Laboratory Animals (Publication DHHS NIH 86-23).

\section{Surgery and histology}

Rats were injected intraperitoneally with $1.3 \mathrm{~mL} / \mathrm{kg}$ of the anesthetic ketamine (Ketapex; Apex Laboratories) at a concentration of $100 \mathrm{mg} / \mathrm{mL}$ and with $0.3 \mathrm{~mL} / \mathrm{kg}$ of the muscle relaxant xylazine (Rompun; Bayer) at a concentration of $20 \mathrm{mg} / \mathrm{mL}$. Each rat was placed in the stereotaxic apparatus (Model 900, Kopf), and the incisor bar was maintained at $\sim 3.3 \mathrm{~mm}$ below horizontal to achieve a flat skull position. A 26-gauge guide cannula (Plastics One) was implanted into the PAG. The right vlPAG was targeted so that the tip of the guide cannula was positioned $5.6 \mathrm{~mm}$ below lambda through a hole drilled $0.1 \mathrm{~mm}$ anterior to and $0.8 \mathrm{~mm}$ lateral to lambda. We implanted cannula into only one hemisphere for two reasons: First, to reduce the possible extent of damage to the PAG and overlying blood vessels; second, because previous research has demonstrated that a unilateral manipulation was sufficient to observe an effect on fear conditioning in a number of brain regions critical for this learning (for example, see Good and Westbrook 1995; LaBar and LeDoux 1996; McNally and Cole 2006). We chose the right PAG to facilitate comparison with our previous experiments (McNally and Cole 2006). The guide cannula was fixed in position with dental cement and anchored with jeweler's screws. A dummy cannula was kept in the guide at all times, except during microinjections. Immediately after surgery, rats were injected intraperitoneally with $0.3 \mathrm{~mL}$ of a $300 \mathrm{mg} / \mathrm{mL}$ solution of procaine penicillin, subcutaneously with $0.1 \mathrm{~mL}$ of a $100 \mathrm{mg} / \mathrm{mL}$ cephazolin sodium, and subcutaneously with $5 \mathrm{mg} / \mathrm{kg}$ carprofen. Rats were allowed $5 \mathrm{~d}$ to recover from surgery, during which time they were handled and weighed daily.

At the conclusion of the experiment, rats were given an overdose of sodium pentobarbital, and their brains were removed. Unfixed brains were sectioned coronally at $40 \mu \mathrm{m}$ through the PAG by use of a cryostat. Every section through the cannula placements in vlPAG was collected on a glass slide and subsequently stained with cresyl violet. Cannula placements were verified at the microscope by a trained observer who was unaware of the subjects' group designations and used the boundaries defined by Paxinos and Watson (1998). The data of any rat were excluded from the primary statistical analysis if the cannula tip was outside the PAG.

\section{Apparatus}

Conditioning and testing were conducted in a set of four identical chambers $(24 \mathrm{~cm}$ [length] $\times 30 \mathrm{~cm}$ [width] $\times 21 \mathrm{~cm}$ [height]). The front and rear walls as well as the hinged lid were constructed of clear Perspex, and the end walls were made of stainless steel. The floor consisted of stainless steel rods, $4 \mathrm{~mm}$ in diameter, spaced $15 \mathrm{~mm}$ apart (center to center). Each chamber stood $2 \mathrm{~cm}$ above a tray of paper pellet bedding (Fibercycle). The chambers were cleaned with water, and the bedding underneath the chambers was changed between rats. These chambers were located individually within sound-attenuating boxes that were painted white. The boxes were illuminated by a red LED so that levels of illumination within the conditioning chambers were 15 $\mathrm{cd} / \mathrm{m}^{2}$.

There were two auditory CSs and two visual CSs. An 82-dB $750 \mathrm{~Hz}$ tone $(0.1 \mathrm{sec}$ rise and fall) and an $82-\mathrm{dB}$ (A scale) clicker ( $20 \mathrm{~Hz}$ spike, rise time $<1 \mu \mathrm{sec}$, decay time, $250 \mu \mathrm{sec}$ ) served as CSB and CSD, respectively, in a fully counterbalanced fashion. These were delivered through speakers mounted in the ceiling of each box. A constant or flashing $(4 \mathrm{~Hz})$ presentation of a white fluorescent light producing an illumination level of $75 \mathrm{~cd} / \mathrm{m}^{2}$ within the chambers served as CSA and CSC, respectively, in a fully counterbalanced fashion. The light was mounted on the ceiling of each box, immediately above the conditioning chamber. All CSs were $30 \mathrm{sec}$ in duration unless otherwise noted and during conditioning co-terminated with the footshock US. This US, unless otherwise noted, was a $0.5-\mathrm{mA}, 1-\mathrm{sec}$ unscrambled AC $50-\mathrm{Hz}$ shock from a constant-current generator that was delivered to the floor of each chamber. The current available to each floor could be adjusted with an in-line milliampere meter. Digital video cameras were mounted on the rear wall of each box and connected to a digital multiplexer in an adjacent room that, in turn, was connected to a DVD recorder. The stimuli used for conditioning were controlled by computer (LabView, National Instruments).

\section{Procedure}

In each experiment rats were submitted to four phases of training: pre-exposure, Stage I, Stage II, and test.

\section{Experiment 1}

Prior to conditioning rats received two days of pre-exposure. During each day rats received four presentations of each CS in a counterbalanced order. Rats were pre-exposed to the stimuli to encourage discrimination between them (Bennett and Mackintosh 1999). Stage I training occurred on Days 1-2. On each day rats received four 30 -sec presentations of CSA co-terminating with footshock. The intertrial interval (ITI) was random, ranging from 60 to $360 \mathrm{sec}$, with a mean of $211 \mathrm{sec}$. Stage II training took place on Day 3. Rats received either two reinforced presentations each of $\mathrm{AB}$ and $\mathrm{CD}$ (two-trial; $n=8$ ) or a single reinforced presentation of each (one-trial; $n=8$ ). All rats received 10-min nonreinforced presentations of the context $4-6 \mathrm{~h}$ after every conditioning session in Stage I and Stage II to reduce levels of contextual conditioning. Finally, on test, rats received three presentations of each CSB and CSD in a fully counterbalanced order.

\section{Experiment 2}

Pre-exposure and Stage I were identical to Experiment 1. Stage II occurred on Day 3. All animals received a single presentation of the compounds $\mathrm{AB}$ and $\mathrm{CD}$, reinforced with either a $0.5-\mathrm{mA}$ footshock (block; $n=7$ ) or a 0.8 -mA footshock (unblock; $n=8$ ). These presentations were separated by a random ITI ranging from 60 to $360 \mathrm{sec}$. All rats received 10-min nonreinforced presentations of the context 4-6 h after every conditioning session in Stage I and Stage II. Test was identical to Experiment 1

\section{Experiment 3}

Pre-exposure and Stage I were identical to Experiment 1. Stage II occurred on Day 3. Rats were injected subcutaneously in the dorsal neck region with $3 \mathrm{mg} / \mathrm{kg}$ naloxone hydrochloride (TocrisCookson) dissolved in $0.9 \%$ (wt/vol) pyrogen-free saline (naloxone; $n=8$ ) or with $1 \mathrm{~mL} / \mathrm{kg} 0.9 \%$ (wt/vol) pyrogen-free saline (saline; $n=7$ ) $15 \mathrm{~min}$ prior to receiving a single reinforced presentation of the compounds $\mathrm{AB}$ and $\mathrm{CD}$. All rats received 10-min nonreinforced presentations of the context 4-6 h after every conditioning session in Stage I and Stage II. Test was identical to Experiment 1.

\section{Experiment 4}

The procedure for pre-exposure was identical to that for Experiment 1 . The procedure for Stage I training was similar to that for Experiment 1, with the single exception that rats were placed in white plastic buckets for $5 \mathrm{~min}$ prior to each conditioning session. We exposed rats to these buckets because the buckets were later used to house animals during vlPAG infusions in Stage II. These exposures were intended to reduce the novelty of being placed in the buckets during Stage II and therefore reduce potential generalization decrements between Stage I and Stage II, which could interfere with blocking.

The procedure for Stage II training was similar to that for Experiment 3, but with the following exceptions. Rats received a 
$0.5-\mu \mathrm{L}$ microinjection of $0.5 \mu \mathrm{g}$ of the selective $\mu$-opioid receptor antagonist CTAP (D-Phe-Cys-Tyr-D-Trp-Arg-Thr-Pen-Thr-NH2; Tocris-Cookson) dissolved in $0.9 \%$ (wt/vol) pyrogen-free saline (CTAP; $n=8)$ or a $0.5-\mu \mathrm{L}$ microinjection of $0.9 \%(\mathrm{wt} / \mathrm{vol})$ pyrogen-free saline (saline; $n=8$ ). For microinjections, rats were placed in the white plastic buckets, and a 33-gauge microinjection cannula was inserted into the guide cannula. The microinjection cannula projected a further $1 \mathrm{~mm}$ ventral to the tip of the guide cannula. The microinjection cannula was connected to a $10-\mu \mathrm{L}$ glass syringe operated by an infusion pump. Drugs were infused over a 2 -min period $(0.25 \mu \mathrm{L} / \mathrm{min})$, and the microinjection cannula was left in place for a further $1 \mathrm{~min}$ to permit diffusion of the injectate. All rats were then placed in the conditioning chamber where they received a single reinforced presentation of the compounds $\mathrm{AB}$ and $\mathrm{CD}$. All rats received 10-min nonreinforced presentations of the context 4-6 $\mathrm{h}$ after every conditioning session in Stage I and Stage II. Test procedure was identical to that of Experiment 1.

\section{Statistics}

Performance during conditioning and test was recorded. The rats were subsequently scored every $2 \mathrm{sec}$ as either freezing (defined as the absence of all movement other than that required for breathing) or not freezing. The numbers of observations scored as freezing were summed and converted to a percentage. A random sample of the data was scored by a second observer, who was unaware of group allocation. The inter-rater reliability exceeded 0.85 . The data presented and used for statistical analysis are those scored by the aware observer. The data were analyzed by means of a planned orthogonal contrast testing procedure, and the Type I error rate was controlled at 0.05 for each contrast tested.

\section{Acknowledgments}

This research was supported by a Discovery Project Grant (DP0343808) from the Australian Research Council to G.P.M. We thank EunA Choi for assistance with surgery.

\section{References}

Bennett, C.H. and Mackintosh, N.J. 1999. Comparison and contrast as a mechanism of perceptual learning? Q. J. Exp. Psychol. 52B: 253-272.

Dickinson, A. 1980. Contemporary animal learning theory. Cambridge University Press, Cambridge, UK.

Dickinson, A., Nicholas, D.J., and Mackintosh, N.J. 1983. A re-examination of one-trial blocking in conditioned suppression. $Q$. J. Exp. Psychol. 35B: 67-79.

Fanselow, M.S. 1998. Pavlovian conditioning, negative feedback, and blocking: Mechanisms that regulate association formation. Neuron 20: $625-627$.

Fanselow, M.S. and Bolles, R.C. 1979. Naloxone and shock elicited freezing in the rat. J. Comp. Physiol. Psychol. 93: 736-744.

Gillan, D.J. and Domjan, M. 1977. Taste-aversion conditioning with expected versus unexpected drug treatment. J. Exp. Psychol. Anim. Behav. Process. 3: 297-309.

Good, A.J. and Westbrook, R.F. 1995. Effects of a microinjection of morphine into the amygdala on the acquisition and extinction of conditioned fear and hypoalgesia in rats. Behav. Neurosci. 109: 631-641.

Gutstein, H.B., Mansour, A., Watson, S.J., Akil, H., and Fields, H.L. 1998. $\mathrm{Mu}$ and kappa opioid receptors in periaqueductal gray and rostral ventromedial medulla. Neuroreport 9: 1777-1781.

Iordanova, M.D., McNally, G.P., and Westbrook, R.F. 2006. Opioid receptors in the nucleus accumbens regulate attentional learning in the blocking paradigm. J. Neurosci. 26: 4036-4045.
James, J.H. and Wagner, A.R. 1980. One-trial overshadowing: Evidence of distributive processing. J. Exp. Psychol. Anim. Behav. Process. 6: 188-205.

Kamin, L.J. 1968. "Attention-like" processes in classical conditioning. In Miami symposium on the prediction of behaviour: Aversive stimulation (ed. M.R. Jones), pp. 9-33. University of Miami Press, Miami.

Kamin, L.J. 1969. Predictability, surprise, attention, and conditioning. In Punishment and aversive behaviour (eds. B. Campbell and R. Church), pp. 279-296. Appleton-Century-Crofts, New York.

Krout, K.E. and Loewy, A.D. 2000. Periaqueductal gray matter projections to midline and intralaminar thalamic nuclei of the rat. $J$. Comp. Neurol. 424: 111-141.

LaBar, K.S. and LeDoux, J.E. 1996. Partial disruption of fear conditioning in rats with unilateral amygdala damage: Correspondence with unilateral temporal lobectomy in humans. Behav. Neurosci. 110: 991-997.

Mackintosh, N.J. 1975a. A theory of attention: Variations in the associability of stimuli with reinforcement. Psychol. Rev. 82: 276-298.

Mackintosh, N.J. 1975b. Blocking of conditioned suppression: Role of the first compound trial. J. Exp. Psychol. Anim. Behav. Process. 1: $335-345$.

Mackintosh, N.J., Dickinson, A., and Cotton, M.M. 1980. Surprise and blocking: Effects of the number of compound trials. Anim. Learn. Behav. 8: 387-391.

Maren, S. and Quirk, G.J. 2004. Neuronal signalling of fear memory. Nat. Rev. Neurosci. 5: 844-852.

Matzel, L.D., Hallam, S.C., and Miller, R.R. 1988. Contribution of conditioned opioid analgesia to the shock-induced associative US-preexposure deficit. Anim. Learn. Behav. 16: 486-492.

McNally, G.P. 1999. Pain facilitatory circuits in the mammalian central nervous system: Their behavioral significance and role in morphine analgesic tolerance. Neurosci. Biobehav. Rev. 23: 1059-1078.

McNally, G.P. and Cole, S. 2006. Opioid receptors in the midbrain periaqueductal gray regulate prediction errors during Pavlovian fear conditioning. Behav. Neurosci. 120: 313-323.

McNally, G.P. and Westbrook, R.F. 2006. Predicting danger: The nature, consequences, and neural mechanisms of predictive fear learning. Learn. Mem. 13: 245-253.

McNally, G.P., Pigg, M., and Weidemann, G. 2004a. Blocking, unblocking, and overexpectation of fear: A role for opioid receptors in the regulation of Pavlovian association formation. Behav. Neurosci. 118: $111-120$.

McNally, G.P., Pigg, M., and Weidemann, G. 2004b. Opioid receptors in the midbrain periaqueductal gray regulate the extinction of Pavlovian fear conditioning. J. Neurosci. 24: 6912-6919.

Padlubnaya, D.B., Parekh, N.H., and Brown, T.H. 2006. Neurophysiological theory of Kamin blocking in fear conditioning. Behav. Neurosci. 120: 337-352.

Paxinos, G. and Watson, C. 1998. The rat brain in stereotaxic co-ordinates, $4^{\text {th }}$ ed. Elsevier, San Diego.

Rescorla, R.A. 1988. Behavioral studies of Pavlovian conditioning. Annu. Rev. Neurosci. 11: 329-352.

Rescorla, R.A. and Wagner, A.R. 1972. A theory of Pavlovian conditioning: Variations in the effectiveness of reinforcement and nonreinforcement. In Classical conditioning II: Current research and theory (eds. A.H. Black and W.F. Prokasy), pp. 64-99. Appleton-Century-Crofts, New York.

Schafe, G.E., Nader, K., Blair, H.T., and LeDoux, J.E. 2001. Memory consolidation of Pavlovian fear conditioning: A cellular and molecular perspective. Trends Neurosci. 24: 540-546.

Wagner, A.R., Mazur, J.E., Donegan, N.H., and Pfautz, P.L. 1980. Evaluation of blocking and conditioned inhibition to a CS signaling a decrease in US intensity. J. Exp. Psychol. Anim. Behav. Process. 6: $376-385$.

Received November 27, 2006; accepted in revised form January 23, 2007. 


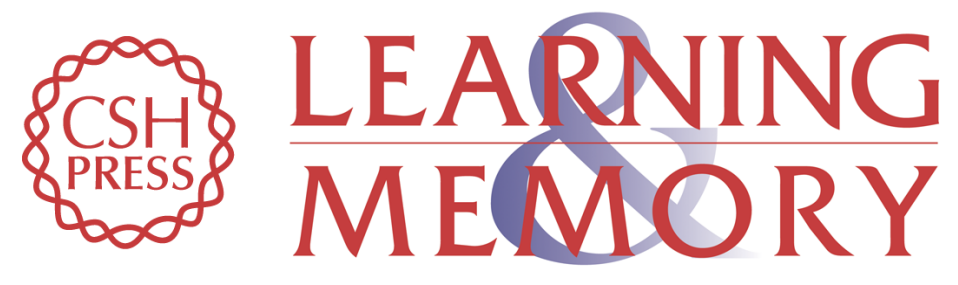

\section{Opioid receptors mediate direct predictive fear learning: Evidence from one-trial blocking}

Sindy Cole and Gavan P. McNally

Learn. Mem. 2007, 14:

Access the most recent version at doi:10.1101//m.489507

References This article cites 25 articles, 3 of which can be accessed free at:

http://learnmem.cshlp.org/content/14/4/229.full.html\#ref-list-1

License

Email Alerting Receive free email alerts when new articles cite this article - sign up in the box at the Service top right corner of the article or click here. 